\section{Formação e prática crítico-reflexiva de professores de inglês em franquias de idiomas}

Training and critical-reflexive practice of English teachers in franchise language schools

Samya Semião FREITAS (UFC) samyafreitas@gmail.com

Recebido em: 26 de abr. de 2020. Aceito em: 21 de maio de 2020.
FREITAS, Samya Semião. Formação e prática crítico-reflexiva de professores de inglês em franquias de idiomas.

Entrepalavras, Fortaleza, v. 10, n. 2, e1890, p. 1-16, maio-ago/2020. DOI: $10.22168 / 2237-6321-21890$.

Resumo: Nesse artigo, objetiva-se investigar a prática crítico-reflexiva de professores de inglês em contexto de franquias de idiomas. Para isso, realizamos um estudo microetnográfico de base descritiva, para o qual contamos com a participação de dez professores de inglês de duas franquias de idiomas em Fortaleza. Para esse estudo, elegemos os dados coletados a partir da aplicação de uma entrevista semiestruturada, a qual objetivou verificar se os professores adotam uma postura crítico-reflexiva sobre seu trabalho. Para a abordagem reflexiva, tomamos como base os ensinamentos de Horikawa (2004), Liberali (2004), Magalhães (2004), Romero (2004), Schön (1997, 2000), dentre outros. Constatamos que a prática crítico-reflexiva dos professores investigados ainda é embrionária e encontra diversos empecilhos impostos pela natureza dessas instituições. Há, na verdade, uma tendência a manterse mais no campo da técnica do que no campo crítico-reflexivo, uma vez que se tende à padronização das ações, o que afeta diretamente a autonomia e a identidade do professor.

Palavras-chave: Ensino de LE. Ensino reflexivo. Franquias de idiomas. 
V. $10(2)$

1-16 maio-ago 2020

Abstract: In this article, we aim to investigate the critical-reflexive practice of English teachers in the context of language franchises. To do so, we carried out a microethnographic study of descriptive basis, for which we counted with the participation of ten English teachers from two language franchises in Fortaleza. For this study, we expose the data collected from the application of a semi-structured interview in order to verify whether teachers adopt a critical-reflexive posture about their work. Regarding the reflexive approach, we take as basis the teachings of Horikawa (2004), Liberali (2004), Magalhães (2004), Romero (2004), Schön (1997, 2000), among others. It appears that the critical-reflexive practice of the investigated teachers is still embryonic and encounters several obstacles imposed by the nature of these institutions. There is, in fact, a tendency for the teacher to maintain his reflection more in the field of technique than in the critical-reflective field, since there is a tendency to standardize actions, which directly affects the teacher's autonomy and identity.

Keywords: FL teaching. Reflective teaching. Franchise language schools.

\section{Introdução}

No atual contexto de ensino de línguas, é essencial que o professor adote uma prática autônoma e reflexiva, visto que o trabalho docente não pode mais se reduzir a pensar em como cumprir as metas que a instituição já tem fixadas.

Na verdade, a solidificação de estudos sobre o processo reflexivo tem propiciado que os professores promovam o diálogo entre as suas crenças e as teorias formais, tornando o processo de ensino e aprendizagem mais iluminado e emancipatório (SILVA, 2005).

Dessa forma, é necessário discutir sobre a implementação da abordagem reflexiva em contextos onde a inserção dessa prática, contudo, ainda se torna problemática, como é o caso dos cursos de franquias.

Nessas instituições, conforme Souza (2016), há muitos fatores que limitam a autonomia do professor. Isso porque é comum que prevaleça um modelo educacional baseado na concepção fordista, em um funcionamento semelhante ao das linhas de montagem. De modo geral, nessas escolas, há uma padronização da estrutura e dos recursos adotados, o que facilita a sua disseminação. Em relação à prática pedagógica, também há a presença de alguns elementos que, inicialmente, já são impostos ao trabalho do professor, como o livro didático, previamente escolhido ou elaborado pela rede de franquias da própria escola. Há, também, normalmente, um treinamento, voltado para a aplicação de um método prescrito pela instituição, a fim de facilitar a homogeneização e o controle das práticas de ensino (MENEGAZZO; XAVIER, 2004). 
O objetivo desse artigo é, pois, investigar a prática críticoreflexiva de professores de inglês em contexto de franquias de idiomas. Para isso, adotamos um estudo qualitativo, de base descritiva, e utilizamos, como instrumento de coleta de dados, a aplicação de uma entrevista semiestruturada com 10 professores atuantes no contexto de duas escolas de idiomas franqueadas de Fortaleza, as quais denominaremos aqui de escola A e de escola B. Sobre o critério de escolha das escolas, atentamos para dois fatores: o maior número de franquias na capital cearense e o maior número de alunos, a partir dos dados da ABF (Associação Brasileira de Franchising ${ }^{1}$ ) e das páginas virtuais dos cursos selecionados. Para a seleção dos professores, adotamos os seguintes critérios: o de maior tempo de atuação na escola, para que o professor já esteja bem familiarizado com o ambiente e a metodologia utilizada; e o de não possuir vínculo com outra instituição de ensino, de forma que não haja influência de outras culturas de trabalho.

\section{Ensino reflexivo de professores de LE}

Considerando as tônicas de investigação em Linguística Aplicada (LA) desde os anos 70, Silva (2005) já atentava para o destaque que os estudos sobre a formação do professor viriam a ter a partir dos anos 2000, englobando aí o professor pré-serviço e em serviço, ou seja, a formação inicial e a formação continuada. De acordo com o autor, em meados da década de 70, o foco de muitas pesquisas em LA ainda recaía sobre os métodos, tidos por ele como uma "maneira pela qual se ensina uma língua estrangeira" (SILVA, 2005, p. 19).

Contudo, na década de 80, o foco passou a ser o aprendiz, levando-se em consideração as suas necessidades; e, nos anos 90, iniciou-se a preocupação com a formação do professor, em especial a do professor de línguas. A reflexão passou, então, a ser um termo muito utilizado por pesquisadores e por formadores de professores para se referir às novas tendências na formação. Ressalta-se, porém, que o termo "reflexivo" não é tomado enquanto adjetivo, visto que a reflexão é inerente ao ser humano, mas como um movimento teórico de compreensão e de desenvolvimento do trabalho docente.

Conforme aponta Castro (2004), o movimento reflexivo teve origem na área da educação com o intuito de entender os motivos que

1 Disponível em: <https://www.portaldofranchising.com.br/guia-de-franquias/segmento/ escolas-de-idiomas/16>. Acesso em 12 mar. 2015. 
V. $10(2)$

1-16

maio-ago

2020

levam o professor a agir de uma determinada maneira em sala de aula. Além disso, ele se desenvolveu contra a tradição do professor como técnico, ou seja, do professor como um mero aplicador das teorias criadas em centros de pesquisas que não levavam em conta a realidade de sala de aula.

Assim, reconhece-se a necessidade de formar profissionais reflexivos, em oposição aos modelos tradicionais centrados no treinamento dos professores e na reprodução do status quo, para a transformação do campo educacional. Isso por que, segundo Leffa (2008), é preciso realizar uma distinção entre formação de professores, a qual envolve teoria, prática e reflexão; e treinamento, que é um direcionamento para a prática e, normalmente, é orientado para o uso de técnicas de ensino, as quais devem ser usadas como se recomenda nos manuais (MOITA LOPES, 1996).

Por isso, desde a década de 1990, a abordagem reflexiva sob um viés crítico tem sido comum nos estudos de formação de professores de língua estrangeira (LE), com o intuito de proporcionar um ensino mais significativo e de criar condições para práticas pedagógicas mais coerentes.

Embora o interesse pela prática reflexiva dos professores seja recente entre alguns estudiosos da área de ensino de línguas, essa ideia não é nova, pois foi inicialmente proposta por John Dewey, no início do século XX, especialmente, em How we think (1933). Nele, o autor faz distinção entre a ação que é rotina e a ação que é reflexiva. A ação rotineira é guiada por uma crença não-crítica na tradição, enquanto a ação reflexiva é gerada por uma consideração cautelosa e consciente de qualquer crença que tenha uma base que a oriente.

Na visão de Dewey, o ato de ensinar não é visto como uma sequência pré-determinada e sequenciada de procedimentos, mas como um contexto de ação sensível com base no pensamento intelectual. Os professores não são vistos como meros transmissores do conhecimento recebido, mas como solucionadores de problemas. O ensino reflexivo é, portanto, uma abordagem holística que enfatiza a criatividade e a sensibilidade do contexto.

Cerca de meio século após as ideias de Dewey, Don Schön, célebre pedagogo e estudioso sobre educação e aprendizagem profissional, publica The Reflective Practitioner: How Professionals Think in Action, no qual a concepção de Dewey é expandida. Ele mostra como os professores podem trazer novas perspectivas às complexidades do ato de ensinar, as quais dificilmente serão compreendidas por pesquisadores que estão distantes da realidade de sala de aula. A perspectiva proposta por ele se dá por meio do envolvimento nos princípios, na prática e nos processos de instrução da sala de aula. 
Dewey (1933) e Schön (1983) são, portanto, os pioneiros nos estudos da prática crítico-reflexiva. Para Dewey, as ações reflexivas devem partir dos próprios professores, com o objetivo de descobrirem quem são, além de quando e como agir em sala de aula. O autor considera que a reflexão deve ser realizada levando-se em consideração o contexto de ação, de forma ativa, persistente e cuidadosa, já que o pensamento reflexivo é "um ativo, prolongado e cuidadoso exame de toda crença ou espécie hipotética de conhecimento, exame efetuado à luz dos argumentos que a apoiam e das conclusões a que chega" (DEWEY, 1933, p. 18).

Schön propõe um modelo baseado em três construtos: a reflexão na ação, a reflexão sobre a ação e a reflexão sobre a reflexão na ação. A primeira, como o próprio nome sugere, ocorre durante a prática; já a segunda, após a prática, durante a revisão da ação em um outro momento, distante do contexto de ação. O terceiro construto já é mais complexo, pois consiste em lançar um olhar para a ação, de forma a refletir sobre a reflexão na ação, em busca de entendimentos sobre o que aconteceu e sobre os motivos que levaram a ação a acontecer daquela forma (SCHÖN, 1997, 2000).

Segundo Freitas e Paniz (2011), diante de situações novas, que fogem à rotina, o professor utiliza a reflexão na ação. Da mesma maneira, a reflexão sobre a ação permite ao professor gerar um repertório de experiências que serão mobilizadas em situações similares, possibilitando ao professor prever dificuldades e utilizar estratégias geradas a partir de erros anteriores. A reflexão sobre a reflexão na ação visa dar conta de novas situações que superam o conhecimento adquirido, exigindo do professor uma investigação de sua prática.

Já Castro (2004) apresenta duas linhas de pensamento para a pesquisa sobre a reflexão na formação de professores: uma que aponta para a convergência entre pensamento e ação, e outra para a reflexão crítica. A primeira acontece por meio da natureza sistemática e continuada da reflexão, e a segunda refere-se à reflexão como instrumento de construção de participantes conscientes e sujeitos do processo socio-histórico.

O professor reflexivo é, pois, aquele que constantemente se autoobserva e se autoavalia, procurando, inclusive, coletar dados para refletir criticamente sobre a sua prática, seja à luz das teorias ou a partir do auxílio de outros sujeitos do contexto de ensino e aprendizagem, pois é interessante que a reflexão também se realize de forma coletiva e colaborativa. 
V. $10(2)$

1-16 maio-ago 2020

Para Horikawa (2004, p.90), exige-se do professor reflexivo uma mudança de identidade, uma vez que a visão deste profissional como "técnico especializado" não se sustenta mais. A ação pedagógica é impregnada de incertezas e de complexidade, e não pode partir de um contexto único e imutável.

Assim, o interesse pela formação de professores como profissionais crítico-reflexivos tem se tornado comum entre diversos pesquisadores. Dentre os anseios das pesquisas na área, está o interesse em promover mudanças nas teorias educacionais que embasam os currículos e a estrutura dos programas de licenciatura e de formação continuada. Além do foco na qualidade da formação, propõe-se também a redefinição do papel do professor, o qual, além de reflexivo, deve tornar-se pesquisador de sua própria ação (MAGALHÃES, 2004, p. 45). Contudo, esses objetivos, de um modo geral, não têm sido atingidos, apesar da existência de diversas pesquisas na área.

Magalhães (2004) propõe que, por meio da linguagem, o professor seja capaz de reconstruir a própria ação e de se desvencilhar de práticas rotineiras. O objetivo seria o professor descrever, analisar e interpretar as suas ações em sala de aula.

Com base no trabalho de Freire (1970), Smyth (1992) propôs quatro formas de ação para orientar os professores no processo reflexivo, visto que não é simples detectar se ele está de fato ocorrendo. Dessa forma, o processo reflexivo seria possível a partir da combinação dos quatro elementos: a descrição (o que faço?); a informação (o que isso significa?); o confronto (o que me levou a agir dessa forma?); e a reconstrução (como posso agir diferente?) (SMYTH, 1992).

Na descrição, há o relato de ações passadas, ou seja, descrevese detalhadamente o que se fez para entender a ação praticada. $\mathrm{Na}$ informação, explicam-se os princípios ou intenções subjacentes à ação tomada, ou seja, informam-se os motivos que definiram uma determinada ação. Já no confronto, avaliam-se criticamente os posicionamentos de ensino e aprendizagem, por meio de uma análise cuidadosa da ação passada; ou seja, a ação é contextualizada nos âmbitos cultural, social e político, em busca da emancipação. Por fim, na reconstrução, buscam-se novas alternativas que visem a transformação do contexto educacional. A reconstrução é, na verdade, a principal meta da ação reflexiva (MAGALHÃES, 2004; HORIKAWA, 2004; LIBERALI, 2004).

Verifica-se, então, a necessidade de uma articulação entre a teoria e a prática, de forma a possibilitar uma visão holística do 
processo de ensino e aprendizagem, assim como uma maior autonomia sobre a sua ação. Daí a necessidade de haver, na formação pré-serviço e na formação continuada, uma abertura para que o professor seja um investigador da própria prática, o que o permitirá nela intervir, se necessário, para efetuar as mudanças cabíveis; ou seja, busca-se oportunizar o (re)pensar e o (re)fazer a própria prática, na tentativa de uma (re)construção constante.

Além dos desafios apresentados, há muitas outras questões a serem superadas no processo de implementação da abordagem reflexiva na formação e na prática docente, dentre eles, o contexto desfavorável a essa prática, o conservadorismo dos currículos e a desarticulação de iniciativas que considerem o contexto de atuação docente (GIMENEZ, 2006).

\section{Investigando a abordagem reflexiva dos professores}

Conforme destacado, a fim de investigar a prática reflexiva dos professores atuantes em dois cursos de franquias de idiomas, foi aplicada uma entrevista semiestruturada pela pesquisadora, com questões pré-estabelecidas, respondidas por escrito, presencialmente, nas franquias. ${ }^{2}$

Na escola A, dentre os 14 professores que compunham o corpo docente, participaram 6 deles, os quais denominaremos de A1, A2, A3, A4, A5 e A6, conforme a identificação do professor pela letra da escola, A, e pelo número, que varia de 1 a 6 . Na escola B, apenas 4, dentre os 8 professores da escola, cumpriam as exigências traçadas para esta pesquisa. Assim, participaram da coleta de dados: B1, B2, B3 e B4. Apresentamos, a seguir, o perfil dos participantes.

${ }^{2}$ Os dados aqui expostos foram coletados a partir de autorização do CEP/UECE, parecer de número 1.115.324, data da relatoria em 19/06/2015. 
V. $10(2)$

1-16

maio-ago 2020

Quadro 1 - Perfil dos participantes

\begin{tabular}{|c|c|c|c|}
\hline \multicolumn{2}{|r|}{ Escola A } & \multicolumn{2}{|r|}{ Escola B } \\
\hline Professor & Descrição & Professor & Descrição \\
\hline A1 & $\begin{array}{llr}\text { Brasileiro, } & 27 & \text { anos; } \\
\text { habilitado em } & \text { Letras/ } \\
\text { português e inglês, } 2 \text { a } 5 \\
\text { anos de experiência, atua na } \\
\text { escola há } 3 \text { anos e meio. }\end{array}$ & B1 & $\begin{array}{l}\text { Brasileiro, } 22 \text { anos; } \\
\text { cursa Ciências Sociais, } \\
\text { experiência de } 2 \text { a } 5 \text { anos, } \\
\text { atua há } 2 \text { anos e } 8 \text { meses } \\
\text { no mesmo sistema de } \\
\text { franquias, mas na escola } \\
\text { B, especificamente, atua } \\
\text { há apenas } 8 \text { meses. }\end{array}$ \\
\hline A2 & $\begin{array}{l}\text { Brasileiro, } 23 \text { anos; cursando } \\
\text { Letras/Inglês, } 2 \text { a } 5 \text { anos de } \\
\text { experiência, atua na escola } \\
\text { há } 3 \text { anos. }\end{array}$ & B2 & $\begin{array}{l}\text { Brasileiro, } 28 \text { anos; cursa } \\
\text { licenciatura em música e } \\
\text { especialização em língua } \\
\text { estrangeira, experiência } \\
\text { de } 2 \text { anos a } 5 \text { anos, atua } \\
\text { na escola há } 2 \text { anos. }\end{array}$ \\
\hline A3 & $\begin{array}{l}\text { Brasileiro, } 22 \text { anos; cursando } \\
\text { Letras/ Alemão, } 2 \text { a } 5 \text { anos } \\
\text { de experiência, atua na } \\
\text { escola há } 3 \text { anos. }\end{array}$ & B3 & $\begin{array}{l}\text { Brasileiro, } 21 \text { anos; cursa } \\
\text { licenciatura em Letras/ } \\
\text { Inglês, experiência de } 2 \text { a } \\
5 \text { anos, atua na escola há } \\
1 \text { ano e } 2 \text { meses. }\end{array}$ \\
\hline$A_{4}$ & $\begin{array}{l}\text { Brasileiro, } 23 \text { anos; formado } \\
\text { em Ciências Sociais, } \\
\text { experiência de menos de } 2 \\
\text { anos, atua há } 1 \text { ano e meio } \\
\text { na escola. }\end{array}$ & B4 & $\begin{array}{l}\text { Brasileiro, } 30 \text { anos; } \\
\text { licenciado em Letras/ } \\
\text { Inglês e especialista em } \\
\text { ensino de língua inglesa; } \\
2 \text { a } 5 \text { anos de experiência, } \\
\text { atua há } 1 \text { ano na escola. }\end{array}$ \\
\hline A5 & $\begin{array}{l}\text { Brasileiro, } 30 \text { anos; cursando } \\
\text { Letras/Inglês, experiência } \\
\text { de menos de } 2 \text { anos, atua na } \\
\text { escola há } 1 \text { ano e meio. }\end{array}$ & $\mathrm{X}$ & $X$ \\
\hline A6 & $\begin{array}{l}\text { Brasileiro, } 28 \text { anos; formado } \\
\text { em Pedagogia, experiência } \\
\text { de } 2 \text { a } 5 \text { anos, atua na escola } \\
\text { há } 1 \text { ano e } 2 \text { meses. }\end{array}$ & $\mathrm{X}$ & $\mathrm{X}$ \\
\hline
\end{tabular}

Fonte: elaborado pela autora.

Inicialmente, interessava-nos saber se os professores eram submetidos a algum treinamento ou formação nos estabelecimentos de atuação e qual o foco desta prática. Diante dessa discussão, formulamos o primeiro questionamento:

Pergunta 01: Você se submeteu a algum tipo de treinamento/ formação antes de iniciar a sua prática na escola em que atua? Se sim, qual o foco desse (a) treinamento/formação? 
Quadro 2 - Respostas dos professores à pergunta 01

\begin{tabular}{|c|c|}
\hline PROFESSOR & RESPOSTA \\
\hline A1 & $\begin{array}{l}\text { Sim, houve um período de aproximadamente um mês de } \\
\text { treinamentos, focando as práticas e metodologias adotadas } \\
\text { pela escola em relação aos diferentes níveis de turmas e } \\
\text { semestres que ela oferece. }\end{array}$ \\
\hline A2 & $\begin{array}{l}\text { Sim, um treinamento para ensinar sobre a fundamentação } \\
\text { teórica da metodologia aplicada e o seu funcionamento em } \\
\text { sala de aula. }\end{array}$ \\
\hline A3 & $\begin{array}{l}\text { Sim. O foco consistia no aprendizado da metodologia dos } \\
\text { livros que seriam abordados nos diversos níveis de ensino da } \\
\text { escola. }\end{array}$ \\
\hline A4 & $\begin{array}{l}\text { Sim. O treinamento focava na metodologia da escola e } \\
\text { auestões administrativas. }\end{array}$ \\
\hline A5 & $\begin{array}{l}\text { Sim. Houve um treinamento para que conhecêssemos a } \\
\text { metodologia da escola, o qual foi, inicialmente, teórico e, } \\
\text { em seguida, realizamos demonstrações de aulas a partir das } \\
\text { orientações que nos foram dadas. Para mim, foi de extrema } \\
\text { importância, pois não tinha experiência em sala de aula de } \\
\text { cursos de línguas. }\end{array}$ \\
\hline A6 & $\begin{array}{l}\text { Sim. Todos os professores têm que se submeter a um } \\
\text { treinamento onde eles conhecem como funciona a metodologia } \\
\text { da escola na prática e como usá-la. Problemas de aprendizado } \\
\text { são citados pela treinadora e os candidatos tem que absorver } \\
\text { o que está sendo passado para, após isso, mostrar na prática } \\
\text { para a treinadora como essa metodologia foi entendida. }\end{array}$ \\
\hline B1 & $\begin{array}{l}\text { Sim. Fui aluna da escola por } 6 \text { meses, no nível avançado, pois } \\
\text { já era fluente mas queria o certificado. Fiz o treinamento para } \\
\text { entender a metodologia e desenvolver algumas habilidades, } \\
\text { como aplicar o conteúdo do livro, falar com o aluno etc. Esses } \\
\text { treinamentos sempre acontecem }\end{array}$ \\
\hline B2 & $\begin{array}{l}\text { Sim. Me submeti a um treinamento de } 2 \text { semanas para } \\
\text { compreender a metodologia linguística do curso de idiomas. }\end{array}$ \\
\hline B3 & $\begin{array}{l}\text { Sim. Aprender sobre a metodologia que a escola trabalhava } \\
\text { e aprender sobre alguns procedimentos mais burocráticos } \\
\text { como preenchimento de documentos. }\end{array}$ \\
\hline B4 & $\begin{array}{l}\text { Sim. Antes de iniciar na escola em que trabalho, me submeti } \\
\text { a um pequeno treinamento de professores, voltado para as } \\
\text { técnicas de ensino de línguas, bem como o uso do material } \\
\text { trabalhado e regras da instituição. Todos os anos a escola } \\
\text { oferece o seu TTC para professores que desejam trabalhar na } \\
\text { instituicão e para professores veteranos. }\end{array}$ \\
\hline
\end{tabular}

No quadro 2, como podemos observar, todos os professores mencionaram a existência de um treinamento focado na metodologia da escola, o qual objetiva também apresentar os procedimentos burocráticos e preparar os docentes para a utilização do material didático. Essa constatação converge com o entendimento apresentado por Leffa (2008) de que, no treinamento, não há espaço para a teoria e para a reflexão, pois o foco é a prática. Ou seja, as instituições parecem adotar um entendimento do professor como um mero aplicador da metodologia de ensino, o que vai contra os pressupostos da abordagem reflexiva. 
V. $10(2)$

1-16

maio-ago

2020

Na segunda pergunta, buscamos investigar se os professores julgam adotar alguma rotina de práticas em sala de aula ditada pelo sistema de franquias, uma vez que a rotinização das práticas não caracteriza um ensino reflexivo.

Pergunta 02: Você segue alguma rotina de práticas em sua sala de aula ditada pelo sistema de franquias ao qual a sua escola pertence? Exemplifique.

Quadro 3 - Resposta dos professores à pergunta 02

\begin{tabular}{|c|c|}
\hline PROFESSOR & RESPOSTA \\
\hline $\mathrm{A} 1$ & $\begin{array}{l}\text { Sim, geralmente nos primeiros semestres, o professor pode utilizar } \\
\text { o português para explicar algum conteúdo gramatical específico e } \\
\text { outra tradição é a não utilização de guadro branco. }\end{array}$ \\
\hline A2 & $\begin{array}{l}\text { Sim, por vezes, utilizo as paredes de vidro para explicar e/ou escrever algo } \\
\text { aos alunos, e uma das práticas adotadas é a não utilizacão de quadro em sala. }\end{array}$ \\
\hline A3 & Sim. Seguimos a metodologia dos livros utilizados da própria escola. \\
\hline A4 & $\begin{array}{l}\text { Sim. Seguir as atividades propostas no livro, motivar o aluno a } \\
\text { permanecer na escola, etc. }\end{array}$ \\
\hline A5 & $\begin{array}{l}\text { Sim. As aulas estão previamente planejadas, então, a aula planejada } \\
\text { para aquele dia deve ser dada. Temos também uma sequência a seguir, } \\
\text { a qual é definida pelo roteiro presente no teacher's guide (TG). Além } \\
\text { disso, há outros procedimentos burocráticos a serem realizados. }\end{array}$ \\
\hline A6 & $\begin{array}{l}\text { Sim. Todas as aulas seguem um modelo e esse modelo tem que ser } \\
\text { igual ao modelo de qualquer escola pertencente a essa franquia. }\end{array}$ \\
\hline B1 & $\begin{array}{l}\text { Há rotinas dentro e fora de sala de aula. O planejamento é um } \\
\text { exemplo, pois o planejamento anual não é realizado pelo professor, } \\
\text { mas pelo diretor e pelo coordenador pedagógico. O professor entra } \\
\text { com as atividades extras. }\end{array}$ \\
\hline B2 & Sim. Práticas como: speaking, writing, reading, listening. \\
\hline B3 & $\begin{array}{l}\text { Sim. Estrutura de aula. A minha escola separa a aula em quatro } \\
\text { momentos: warm up, engage, study e activate. }\end{array}$ \\
\hline B4 & $\begin{array}{l}\text { Sim. A rotina que devo seguir se trata do preenchimento dos diários de } \\
\text { classe, fazendo a frequência dos alunos e o registro do conteúdo trabalhado } \\
\text { na aula, detalhando o número da atividade do livro e das atividades do } \\
\text { workbook para casa (não faz parte da rotina da escola a correção do } \\
\text { workbook em sala de aula). Além disso, há uma plataforma online na qual } \\
\text { os alunos devem responder as tarefas a cada fim de unidade do livro. } \\
\text { Tais atividades são corrigidas automaticamente pela própria plataforma. } \\
\text { É também parte da rotina do professor entrar na plataforma e registrar } \\
\text { no diário de classe a nota do aluno dada pela plataforma. }\end{array}$ \\
\hline
\end{tabular}

Todos os professores afirmaram seguir algum tipo de rotina ditada pela escola. Dentre os elementos que se incluem nessa rotinização, os professores mencionaram a determinação do uso de alguns recursos didáticos (A1, A2); a utilização da L1 para a comunicação do professor com os alunos (A1); e o uso do livro didático (conforme A3 e A4), o qual orienta a prática do professor (A5), e permite uma padronização das aulas (A6). Além disso, o cumprimento do planejamento já realizado por terceiros também foi mencionado (A5, B1). 
Por meio do discurso desses participantes, observamos que a adoção do ensino reflexivo encontra diversos empecilhos impostos pela natureza dessas instituições. Isso porque as ações realizadas tendem para o que Dewey (1933) classificou como ação-rotina, orientada por uma crença não-crítica sobre o que é estabelecido pelas escolas, e não a partir de uma análise criteriosa e atenta por parte do professor.

Então, para que pudéssemos investigar a margem de autonomia dada ao professor, no que se refere à inserção de técnicas e/ou atividades diversas daquelas do método/abordagem utilizado, elaboramos a terceira questão:

Pergunta 03: A escola em que você trabalha permite a inserção de técnicas e/ou atividades diferentes daquelas oriundas do método/abordagem utilizado? Você o faz? Exemplifique.

Quadro 4 - resposta dos professores à pergunta 03

\begin{tabular}{|c|c|}
\hline PROFESSOR & RESPOSTA \\
\hline $\mathrm{A1}$ & Sim, de vez em quando, trago músicas ou jogos para a sala de aula. \\
\hline A2 & $\begin{array}{l}\text { Sim, posso substituir alguma atividade das aulas de output por } \\
\text { alguma atividade da minha escolha, mas não sempre. Às vezes, levo } \\
\text { alguma dinâmica ou música. }\end{array}$ \\
\hline A3 & $\begin{array}{l}\text { Nâ muito. Existe um material à parte que pode ser utilizado pelos } \\
\text { professores mas eu não os utilizo o bastante. }\end{array}$ \\
\hline A4 & $\begin{array}{l}\text { Sim, permite a utilização de certos materiais extras como músicas, } \\
\text { jogos, mas com certa frequência que não atrapalhe o andamento } \\
\text { normal da aula. Sim, utilizo essas atividades, para modificar um } \\
\text { pouco a rotina e porque essas podem conter rico material pedagógico. }\end{array}$ \\
\hline A5 & $\begin{array}{l}\text { Nas aulas ímpares, é mais difícil, pois são aulas de apresentação de } \\
\text { conteúdo e temos um tempo limitado para finalizar a lição. Nas aulas } \\
\text { pares temos mais liberdade e podemos trazer atividades extras e realizar } \\
\text { alteracões em algumas atividades para que não fiquem tão repetitivas. }\end{array}$ \\
\hline A6 & $\begin{array}{l}\text { Sim. Átividades extras como música, textos e vídeos além dos que } \\
\text { já aparecem no material didático são permitidos e eu trabalho com } \\
\text { todos eles sempre que possível. }\end{array}$ \\
\hline B1 & $\begin{array}{l}\text { Permite. Não realizo atividades tão diferentes do método, mas } \\
\text { tenho autonomia para criar atividades. Uma vez, na minha turma de } \\
\text { crianças utilizei uma atividade do livro de outra forma, pedi para que } \\
\text { elas realizassem o conversation com nessoas de fora da turma. }\end{array}$ \\
\hline B2 & $\begin{array}{l}\text { Sim. Abordamos diversas atividades diferentes que nos permitem } \\
\text { inserções de novas técnicas como aulas de música, seriados, jogos e etc. }\end{array}$ \\
\hline B3 & $\begin{array}{l}\text { Sim. Sim. O método abordado na minha escola não se aprofunda } \\
\text { muito na gramática e as vezes sinto que meus alunos se sentem } \\
\text { perdidos, então tento levar materiais com exercícios focados na } \\
\text { gramática. }\end{array}$ \\
\hline B4 & $\begin{array}{l}\text { Geralmente, sigo à risca cumprindo as atividades sugeridas pelo livro. } \\
\text { Entretanto, algumas vezes eu mesmo preparo atividades diferentes, } \\
\text { tratando de assuntos que o livro não aborda como, símbolos } \\
\text { fonéticos ou uma outra atividade que exercite a memória de curto } \\
\text { prazo a fim de tornar a aula mais lúdica e trabalhar vocabulário para } \\
\text { aprendizes visuais. }\end{array}$ \\
\hline
\end{tabular}


V. 10 (2) 1-16 maio-ago 2020

A maioria dos professores relatou ter uma margem de autonomia para inserir atividades e/ou técnicas diversas da metodologia da escola. No entanto, essa constatação ainda não é suficiente para que se caracterize a prática como ensino reflexivo, pois, para isso, é preciso a adoção de uma abordagem holística de atuação, de forma que o professor possa determinar suas ações a partir da sensibilidade do contexto.

De acordo com o relato dos professores, quando há a inserção de técnicas e/ou atividades diferentes daquelas oriundas do método/ abordagem, esse uso se limita ao uso de músicas, jogos etc. para diversificar as atividades, sem, contudo, apresentar um objetivo de aprendizagem claro, como expressam A4 e A5. Dentre os fatores que impossibilitam a diversificação, esses professores mencionam a limitação do tempo de aula, o qual é reservado para o cumprimento das rotinas estabelecidas. B3 e B4 foram os únicos professores que demonstraram inserir atividades a partir das necessidades dos alunos. B3, por perceber deficiências quanto ao trabalho com a gramática, diz utilizar um material próprio à parte. B4, por sua vez, embora afirme que, de um modo geral, procura seguir as atividades do livro, às vezes realiza um trabalho com símbolos fonéticos, além de atividades que exercitem a memória de curto prazo e de atividades de vocabulário. Observa-se, pois, que B4 é o professor que demonstra uma maior consciência do propósito das atividades que insere diversas daquelas propostas pelo método ou pelo material da escola. Vale reiterar que B4 é o professor com o maior nível de escolaridade entre os participantes, pois possui licenciatura em Letras-Inglês e é especialista na área de ensino de língua inglesa.

Contudo, julgamos que há, entre os professores investigados, independentemente da formação, uma construção identitária muito forte do professor como aplicador de procedimentos e de técnicas, o que exige, conforme Horikawa (2004), um trabalho de mudança de identidade para que se oportunize uma abordagem reflexiva.

As perguntas 4 e 5 foram elaboradas, de forma mais específica, com foco na atividade reflexiva. Na quarta pergunta, indagamos se os professores têm o hábito de refletir sobre a ação realizada a fim de promover a aprendizagem dos alunos, conforme apresentado a seguir.

Pergunta 04: Você tem o costume de refletir sobre a sua ação em sala de aula a fim de buscar possíveis soluções para as dificuldades e os conflitos enfrentados? 
Quadro 5 - resposta dos professores à pergunta 04

\begin{tabular}{|c|c|}
\hline PROFESSOR & RESPOSTA \\
\hline $\mathrm{A} 1$ & $\begin{array}{l}\text { Às vezes, faço como forma de autoavaliação. Também recebo e dou } \\
\text { feedbacks aos meus alunos. }\end{array}$ \\
\hline A2 & As vezes o faço buscando melhorar a mim e a minha atuação em \\
\hline A3 & $\begin{array}{l}\text { Sim. Sempre procuro a melhor forma de passar o conteúdo abordado } \\
\text { para os aprendizes da forma que mais se adeque a eles. }\end{array}$ \\
\hline A4 & $\begin{array}{l}\text { Sim. Todas as vezes penso em coisas para melhorar minha prática } \\
\text { em sala de aula, a aprender a lidar com os diferentes níveis e pessoas. }\end{array}$ \\
\hline A5 & Sempre. \\
\hline A6 & $\begin{array}{l}\text { Sim. A cada semestre percebo como lidar melhor com as dificuldades } \\
\text { dos alunos, então eu sempre estou prevendo as possíveis dúvidas } \\
\text { para explicar antes mesmo que elas apareçam. }\end{array}$ \\
\hline B1 & $\begin{array}{l}\text { Sempre. Quando eu pego níveis de turmas que já havia pego antes } \\
\text { como o básico II, é possível prever alguns erros, alguns problemas e } \\
\text { pensar em alternativas. }\end{array}$ \\
\hline B2 & Sim. Sempre. \\
\hline B3. & Sim. \\
\hline B4 & $\begin{array}{l}\text { Sim, sou um pouco autocrítico. Acredito que quanto mais é conhecida } \\
\text { uma atividade pelo professor, melhor ela é explicada em turmas } \\
\text { seguintes e, consequentemente, melhor executada também pelos } \\
\text { alunos, embora sendo inéditas para eles. Porém, devo confessar } \\
\text { que ultimamente estou sem tempo para tentar aprimorá-las, } \\
\text { especialmente aquelas que eu mesmo desenvolvo. }\end{array}$ \\
\hline
\end{tabular}

A maioria dos professores respondeu afirmativamente à questão. Apesar de mencionarem a realização de processos próprios da abordagem reflexiva, como a autoavaliação (A1), a autocrítica (B4) e a realização de melhorias para a prática (A2, A3, A4, A6 e B1), percebemos que a abordagem crítico-reflexiva ainda é embrionária, pois os empreendimentos realizados são bem pontuais e se resumem a tentativas baseadas em crenças não-críticas acerca do que os professores acreditam que possa favorecer as suas práticas.

Também julgamos relevante investigar se os professores adotavam uma abordagem colaborativa durante os treinamentos realizados pelas escolas, ou em outro momento, uma vez que a prática colaborativa é apontada como uma possibilidade de gerar oportunidades de reflexão, de crítica e de negociação entre os participantes de discussões conduzidas na escola. A partir dessa interação com o outro é que se constitui o profissional autorreflexivo. Por esse motivo, inserimos a quinta pergunta, conforme exposto a seguir.

Pergunta 05: Você tem o hábito de compartilhar (com o seu coordenador e/ou com outros professores) as suas experiências positivas e negativas vivenciadas em sala de aula com o objetivo de contribuir para a sua formação e a dos demais envolvidos? 
V. $10(2)$

1-16

maio-ago

2020

Quadro 6 - resposta dos professores à pergunta 05

\begin{tabular}{|c|c|}
\hline PROFESSOR & RESPOSTA \\
\hline A1 & Muito, inclusive há reuniões pedagógicas para isso. \\
\hline A2 & $\begin{array}{l}\text { Sim, temos um espaço reservado para essa prática no momento } \\
\text { da reunião de professores. }\end{array}$ \\
\hline A3 & Sim. \\
\hline $\mathrm{A}_{4}$ & $\begin{array}{l}\text { Sim, as positivas porque são importantes de serem compartilhadas } \\
\text { para que sejam repetidas por mim e pelos outros. E as negativas } \\
\text { para que possa ser discutida a fim de achar soluções para os }\end{array}$ \\
\hline A5 & $\begin{array}{l}\text { Sim. Sempre comento com outros professores as dificuldades } \\
\text { encontradas e compartilhamos algumas alternativas encontradas } \\
\text { para determinados problemas. Há também reuniões quinzenais } \\
\text { para que alguns pontos sejam discutidos, mas sei que há } \\
\text { determinados parâmetros que não podem ser mudados. }\end{array}$ \\
\hline A6 & $\begin{array}{l}\text { Sim. Sempre compartilho com os coordenadores, pois assim } \\
\text { eles já passam para os meus colegas o que for mais interessante }\end{array}$ \\
\hline B1 & $\begin{array}{l}\text { Bastante. Eu divido atividades extras e apoio professores com } \\
\text { dificuldades. }\end{array}$ \\
\hline B2 & Sim, nas reuniões pedagógicas entre coordenação e professores. \\
\hline B3. & Sim. $\quad$. \\
\hline B4 & $\begin{array}{l}\text { Sim, acho isso importante. Todavia procuro escutar mais meus } \\
\text { colegas do que compartilhar minhas experiências com eles. } \\
\text { Aprendo muito quando ouço experiências de outros professores, } \\
\text { tanto as positivas quanto as negativas. }\end{array}$ \\
\hline
\end{tabular}

Fonte: elaborado pela autora.

Os professores de ambas as escolas afirmaram cultivar o hábito, seja entre coordenadores e professores, ou apenas entre professores, de compartilhar experiências para desenvolver a prática e para amenizar algumas dificuldades. Contudo, constatamos que esse processo ainda é realizado de forma incipiente. Embora sejam oportunizadas discussões sobre aspectos da prática, mesmo que em situações bem específicas, dificilmente haverá espaço para a efetiva realização das etapas de confronto e de reconstrução, uma vez que as escolas tendem a uma padronização das práticas, o que torna problemática a sua contestação.

Dessa forma, acreditamos que esse processo ainda não se caracterize como colaborativo, pois, conforme Cristovão (2009), o objetivo da colaboração é refletir sobre o novo e o velho, a partir de questionamentos acerca de determinados valores e ações, problematizando as escolhas realizadas. Assim, por meio dos possíveis conflitos existentes na relação entre professores e coordenadores, por exemplo, as negociações são tidas como ferramentas que possibilitam a formação contínua do professor, por meio das quais "repensam-se os papéis do professor, dos alunos e do material didático, e transformações começam a ocorrer" (CRISTOVÃO, 2009, p. 182). 
Embora as reuniões mencionadas pelos professores ainda apresentem limitações para que se realize, de fato, uma análise reflexiva, julgamos que esses eventos interativos, se reformulados, são situações propícias para a realização do processo reflexivo-colaborativo entre os professores.

\section{Considerações finais}

Esse artigo objetivou investigar a prática crítico-reflexiva de professores de inglês em contexto de franquias de idiomas. A partir da análise empreendida, observamos que, em ambas as escolas, a homogeneização, característica dos sistemas de franquias, tende a limitar a autonomia dos professores. Na verdade, há um foco muito grande na metodologia em detrimento do papel interventivo do professor.

Constatamos que a prática crítico-reflexiva dos professores investigados ainda é embrionária e encontra diversos empecilhos impostos pela natureza dessas instituições. De modo geral, observou-se uma tendência do professor a manter a sua reflexão mais no campo da técnica, como um mero aplicador da metodologia e dos procedimentos burocráticos da escola, do que no campo crítico-reflexivo.

Embora os professores realizem alguns processos da abordagem reflexiva, como a autoavaliação e a autocrítica, essas práticas ainda não são suficientes para caracterizar um ensino reflexivo, que tem como principal meta a compreensão e o desenvolvimento do trabalho docente. Inclusive, nos contextos investigados, julgamos que não haja uma diferença significativa entre a atuação dos professores com formação ou não na área, pois, uma vez que se tende à padronização das ações, afeta-se diretamente a identidade do professor.

\section{Referências}

CASTRO, S.T.R. A linguagem e a reconstrução da ação docente: um estudo com professoras de inglês de um curso de Letras. In: MAGALHÃES, M. C. C. (org.). A formação do professor como um profissional crítico: linguagem e reflexão. 2. ed. Campinas: Mercado de Letras, 2004. p.105-118.

CRISTOVÃO, V.L.L. Sequências didáticas para o ensino de línguas. In: DIAS, R.; CRISTOVÃO, V. L. (Org.). o livro didático de língua estrangeira: múltiplas perspectivas. Campinas: Mercado de Letras, 2009. p.305-344.

DEWEY, J. How we think. Lexington: D. C. Heath, 1933. 234p.

FREIRE, P. Pedagogia do Oprimido. Rio de Janeiro: Ed. Paz e Terra, 2005. 107p. 
V. $10(2)$

1-16 maio-ago 2020

FREITAS, D; PANIZ, C. 0 uso de diários na formação inicial de professores. Jundiaí: Paco Editorial, 2011. 88p.

GIMENEZ, T. Tornando-se professores de inglês: experiências de formação inicial em um curso de letras. In: VIEIRA-ABRAHÃO, M. H. (org.) Prática de ensino de língua estrangeira: experiências e reflexões. Campinas: Pontes Editores, 2004. p. 171-187.

HORIKAWA, A. Y. Interação pesquisador-professor: por uma relação colaborativa. In: MAGALHÃES, M. C. C. (Org.). A formação do professor como um profissional crítico: linguagem e reflexão. 2. ed. Campinas: Mercado das Letras, 2004. p. 89-104.

LEFFA, V. J. Aspectos políticos da formação do professor de línguas estrangeiras. In: LEFFA, V. J. (org.) 0 professor de línguas estrangeiras: construindo a profissão. Pelotas: [s.n], 2008. p. 333-355.

LIBERALI, F.C. As linguagens das reflexões. In: MAGALHÃES, M.C.C. (org.). A formação do professor como um profissional crítico: linguagem e reflexão. 2. ed. Campinas: Mercado de Letras, 2004. p. 63-104.

MENEGAZZO, R.E.; XAVIER, R.P. Do método à autonomia do fazer crítico. Trabalhos em Lingüística Aplicada, v. 43, n. 1, 2004. p. 115-126.

MOITA LOPES, L. P. A formação teórico-crítica do professor de línguas: o professor pesquisador. In: MOITA LOPES, L. P. Oficina de linguística aplicada.

ROMERO, T. R. S. Características linguísticas do processo reflexivo. In: MAGALHÃES, M. C. C. (org.). A formação do professor como um profissional crítico: linguagem e reflexão. 2. ed. Campinas: Mercado de Letras, 2004. p. $135-144$.

SCHÖN, D. Educando o profissional reflexivo. São Paulo: Artmed, 2000. 256p.

SCHÖN, D. Formar professores como profissionais reflexivos. In: NÓVOA, A. (Org.). Os professores e a sua Formação. Lisboa: Publicações D. Quixote, 1997. p. 77-91.

SCHÖN, D. The Reflective practitioner: How Professionals Think in Action. Abingdon: Routledge, 1992 [1983]. 374 p.

SILVA, K. A. Crenças e aglomerados de crenças de alunos ingressantes em Letras (inglês). 2005. 243 f. Dissertação (Mestrado em Linguística Aplicada) Programa de Pós-Graduação em Linguística Aplicada, Universidade Estadual de Campinas, Campinas, 2005.

SMYTH, J. Teacher's work and the politics of reflection. American Educational Research Journal, v. 29, n. 2, 1992. p. 267-300.

SOUZA, C.F. Ecos do ser e do estar: um estudo discursivo acerca do trabalho do professor de inglês de cursos livres. 2016. 231 f. Dissertação (Mestrado em Estudos de Linguagem) - Programa de Pós-Graduação em Estudos de Linguagem, Universidade Federal Fluminense, Niterói, 2016. 